\title{
DA LITERATURA AO CINEMA: REFLEXÕES SOBRE COMUNICAÇÃO PARA A PAZ EM "ME CHAME PELO SEU NOME"
}

\author{
FROM LITERATURE TO CINEMA: REFLECTIONS ON COMMUNICATION FOR PEACE IN \\ "CALL ME BY YOUR NAME"
}

Alex Carolino Francisco ${ }^{1}$

Submetido em: $27 / 04 / 2020$

Avaliado em: 28/09/2020

Aprovado em: 23/02/2021

\section{RESUMO}

Os estudos para a paz (Peace Studies) nos dão a perspectiva das estruturas que legitimam a violência cultural na sociedade e mostram como os meios de comunicação contribuem para naturalizar condutas e discursos violentos. A partir das definições de Johan Galtung e de pesquisa bibliográfica, este artigo analisa o trecho conhecido como "monólogo de Perlman", do livro Me Chame pelo Seu Nome (2017), transposto para o audiovisual, e o classifica dentro das características práticas de comunicação para cultura de paz propostas por Alex Iván Arévalo Salinas. Assim, tecemos algumas inferências a respeito da literatura e do cinema da obra supracitada e refletimos sobre como os produtos culturais e sua estrutura organizacional na transposição de linguagens podem romper com violências institucionalizadas contra os LGBTIs.

PALAVRAS-CHAVE: : Comunicação para a paz. Violência cultural. Literatura. Cinema. Transformação de conflitos.

\section{ABSTRACT}

Peace Studies give us the perspective of the structures that legitimize cultural violence in society and show how the media contribute to naturalize violent conduct and discourse. Based on Johan Galtung's definitions and bibliographic research, this article analyzes the passage known as "Perlman's monologue", from the book "Call Me By Your Name" (2017), transposed to the movie, and classifies it within the practical characteristics of communication for culture of peace proposed by Alex Iván Arévalo Salinas. We make some inferences about the literature and cinema of the aforementioned work and reflect on how cultural products and their organizational structure in the transposition of languages can break with institutionalized violence against LGBTIs.

KEYWORDS: Communication for peace. Cultural violence. Literature. Cinema. Conflict transformation.

\footnotetext{
${ }^{1}$ Mestrando em Ciências da Comunicação pela Universidade de São Paulo (ECA/USP). Especialista em Cinema e Linguagem Audiovisual pela Estácio de Sá. Graduado em Comunicação Social - Jornalismo pela Universidade Guarulhos (UNG). Docente nos cursos de Jornalismo, Publicidade e Propaganda e Fotografia da UNG. Dramaturgo e roteirista com formação pelo Centro Universitário Belas Artes, onde lecionou o curso livre de Roteiro de Cinema por cinco anos, e Academia Internacional de Cinema. Publicou dois livros e é vencedor do Prêmios Literários 2017 da Fundação Cultural do Pará com a dramaturgia A Nevasca. Tem experiência em jornalismo cultural com passagem pelos cadernos de cultura dos jornais Agora São Paulo (Grupo Folha) e Diário de Guarulhos, e como relações públicas dos canais de TV por assinatura da Turner do Brasil. É subeditor do portal LeiaJá, editor da revista digital Cultcom e curador da galeria virtual CAM. Correio eletrônico: alexcfrancisco@ gmail.com
} 


\section{INTRODUÇÃO}

Em meio à agenda contemporânea em que grupos sócio-acêntricos ${ }^{2}$ fomentam debates que apontem caminhos para o desenvolvimento intercultural de uma sociedade, o livro, instrumento de comunicação dotado de multiplicidade de papéis, sentidos, funções históricas e que estabelece uma relação de proximidade entre a sociedade e o progresso, age como fermento (FEBVRE e MARTIN, 2017) ao fazer a experiência da leitura ir além do impresso para forjar uma mentalidade nova.

Ao mesmo tempo em que conserva "pensamentos antigos" e faz circular "pensamentos novos", o livro sobrevive não só para permitir que se ultrapasse a barreira do tempo e preserve informações e registros de modos de vida, como também serve de base para compreender a formação de determinada época e suas implicações na vida contemporânea. Pode também ser utilizado como instrumento para comunicar a cultura de paz, que atua na resolução de problemas por meio do diálogo, da negociação e da mediação, para tornar a guerra e a violência inviáveis (NOLETO, 2010), e que respeita os direitos individuais, assegura e sustenta a liberdade de opinião e se empenha em prevenir conflitos, resolvendo-os em suas fontes, para a consolidação da paz positiva.

É a partir das reflexões propostas pelo sociólogo norueguês Johan Galtung, que funda o Peace Institute Research nos anos 1960, uma evolução dos estudos para a paz (Peace Studies), que compreendemos a paz positiva construída sobre os ideais de equilíbrio, cooperação e integração (CABRAL e SALHANI, 2017) e que é preciso, nos estudos para a paz, debruçar-se nos entremeios dos conflitos, cuja raiz

[...] está sempre em uma tradição, isto é, em objetivos incompatíveis. Um conflito geralmente tem componentes de atitude e comportamento. As atitudes são condicionadas pelo subconsciente coletivo, cultura profunda, gênero, classe etc. E o comportamento é condicionado por padrões adquiridos em situações de conflito. (GALTUNG, 2003)

Muitos desses conflitos estão ligados a institucionalização da violência, presente nas mais diversas organizações que norteiam a vida do indivíduo, do nascimento até à morte. São condutas e discursos violentos difundidos por grupos que atuam na manutenção do próprio poder com um tipo de violência que não se dá apenas em casos isolados, mas principalmente em processos organizacionais recorrentes e não individualizados, que fazem da violência, muitas vezes, um elemento institucional legitimado pela própria cultura das organizações (CABRAL, GONÇALVES e SALHANI, 2018, p. 252).

Nesse contexto, sugerimos uma reflexão sobre como as atitudes de intolerância ao público LGBTI ${ }^{3}$ (Lésbicas, Gays, Bissexuais, Travestis, Transexuais e Intersexo) que estão ligadas, a partir das definições de Galtung (2003), à violência cultural, cujos aspectos legitimam a violência direta ${ }^{4}$ ou estrutural ${ }^{5}$ contra esse grupo. Ou seja, a violência cultural não mata ou mutila como a violência direta, mas sua concepção nos ajuda a entender onde residem os comportamentos, crenças, ideologias, preconceitos e outros discursos sociais, bem como os produtos culturais, em que não são possíveis identificar vítimas e agressores de maneira clara, já que estão disseminados na sociedade. Assim, um ato de violência direta, como o recolhimento de livros, proibição de filmes e a censura a outras manifestações artísticas de temática homossexual tem por trás aspectos culturais oriundos de um conflito estruturado em pensamentos e ações que o legitimam.

Intrínseca aos estudos para a paz, a transformação de conflitos sugere que a mudança cultural advém do entendimento da raiz conflito e da percepção de um indivíduo sobre o outro de maneira prescritiva. Como

\footnotetext{
${ }^{2}$ Ricardo Alexino Pereira usa o termo sócio-acêntrico para se referir aos segmentos étnico-sociais (afro-brasileiros, homossexuais, mulheres, idosos, entre outros) considerando que são grupos que podem ser melhor entendidos no contexto da neocidadania midiática e que trazem questões de comportamento e cidadania no contexto da mídia, ou seja, de protagonização. Disponível em: < https://jornal.usp.br/artigos/odesgaste-de-termos-como-empoderamento-protagonismo/>. Acesso em 28 de agosto de 2019.

${ }^{3}$ Termo adotado pela Organização das Nações Unidas (ONU). Disponível em: <https://nacoesunidas.org/tema/lgbti/>. Acesso em 19 de agosto de 2019.

${ }^{4}$ Aquela em que agressores e vítimas são identificáveis e em que ocorre o ato físico e comprobatório da violência.

${ }^{5}$ Aquela em que as vítimas são identificáveis, mas os agressores são ocultados por estruturas ou sistemas sociais, políticos, econômicos, etc.
} 
aponta Spangler

as consequências destrutivas de um conflito podem ser modificadas ou transformadas de modo que as autoimagens, relações e estruturas sociais melhorem como resultado do conflito, em vez de serem prejudicados por ele. Normalmente, isso envolve a transformação das percepções sobre as questões, ações e outras pessoas ou grupos. (SPANGLER, 2003)

Sob o guarda-chuva da produção cultural, este artigo tem como objeto um trecho do livro Me Chame pelo Seu Nome (2017) e o compara com sua respectiva cena no filme homônimo (2018) para identificar possíveis transformações de conflitos na divulgação de uma cultura de respeito pela diversidade a partir da narrativa ficcional. Para isso, opta pela análise de conteúdo para investigar o que está manifesto na literatura e no roteiro cinematográfico da obra supracitada, com a finalidade de interpretá-los e conhecer aquilo que está por trás das palavras sobre as quais se debruça (BARTIN, 2016). A metodologia é aplicada a partir da técnica de análise de asserção avaliativa, que busca compreender as atitudes do locutor quanto aos objetivos do que ele fala.

Parte do princípio de que a linguagem representa e reflete diretamente aquele que a utiliza. Por conseguinte, podemos nos contentar com os indicadores manifestos, explicitamente contidos na comunicação, para fazer inferências a respeito da fonte de emissão. (BARDIN, 2016)

\section{DIÁLOGOS ENTRE EMISSOR E RECEPTOR}

Call Me By Your Name é um romance de temática homossexual do doutor em Literatura Comparada pela
Universidade Harvard (EUA) e escritor egípcio-americano André Aciman, publicado nos Estados Unidos em 2007, pela Farrar, Straus and Giroux 6 . O livro foi lançado no Brasil apenas em 2018, pela editora Intrínseca, com o título de Me Chame pelo Seu Nome, impulsionado pela repercussão da versão cinematográfica de 2017. O filme ${ }^{7}$ dirigido por Luca Guadagnino recebeu quatro indicações ao Oscar e ganhou o de Melhor Roteiro Adaptado $^{8}$ pelo trabalho do roteirista veterano James Ivory, de 91 anos, que, em 1987, também roteirizou para o cinema outra literatura de temática LGBTI, Maurice (1971), escrita pelo londrino E. M. Forster (1879-1970).

Para entendermos o contexto e os objetivos da história escrita por Aciman e da adaptação de Ivory, começamos por comparar as sinopses do livro e do filme:

\begin{tabular}{|l|l|}
\hline Sinopse extraída do livro de 2018 & Sinopse extraída do filme de 2017 \\
\hline E verão na Riviera Italiana. Como todos os & Verão de 1983 na Itália. Elio (Timothée \\
anos, o pai de Elio recebe na casa da familia & Chalamet), um rapaz precoce de 17 anos, \\
um jovem acadêmico para ajudá-lo com suas & passa os dias na vila de sua família \\
pesquisas universitárias. O escolhido dessa & transcrevendo e tocando música clássica, \\
temporada é Oliver, um americano tão & lendo e paquerando sua amiga Marzia. Um \\
atraente quanto evasivo, que aproveita o & dia, Oliver (Armie Hammer), um charmoso \\
clima ensolarado do Mediterrâneo para & estudante americano que fará estágio de \\
trabalhar e, claro, se divertir nas horas vagas. & verão chega para ajudar o pai de Elio, um \\
Aos poucos, entre banhos de piscina, & eminente professor. Elio e Oliver descobrem \\
discussões sobre arte e literatura, passeios & a beleza estonteante do despertar do desejo \\
de bicicleta, festas no vilarejo e ausências & durante um verão que irá mudar suas vidas \\
repentinas, um romance intenso como o & para sempre. \\
verão floresce entre Elio e o visitante. & \\
Conforme tateiam o instável e desconhecido & \\
terreno que os separa, aquilo que inicialmente \\
parecia uma relação de indiferença supera o \\
medo e a obsessão para culminar em uma \\
troca tão íntima que marcará os dois pela vida \\
inteira.
\end{tabular}

Podemos inferir que enquanto a sinopse do livro é poética e não determina a idade do personagem Elio, a do filme auxilia o espectador a encontrar um traço temporal como referência, já que essa construção será definida na imagem, e sintetiza os sentimentos que envolvem a relação de Elio e Oliver ao substituir um conjunto de definições complexas, como "tateiam o instável e desconhecido terreno que os separa" e "uma relação de

Editora fundada em 1946, conhecida por publicar uma lista internacional de ficção literária, não-ficção, poesia e livros infantis. Disponível em: $<$ https://us.macmillan.com/fsg/>. Acesso em 28 de agosto de 2019.

Recebeu o "American Film Institute como um dos dez melhores filmes de 2017; foi indicado ao Golden Globe e ao Critics's Choice Awards recebeu o Grand Prix na categoria longa-metragem no do festival LGBTQ+ Chéries-Chéris; e levou quatro prêmios Dorian Awards 2017/18, sendo dois deles nas categorias Filme do Ano e Filme do Ano LGBTQ" (FREITAS, 2018). Disponível em: < http://portalintercom.org.br/anais/ nacional2018/resumos/R13-1983-1.pdf>. Acesso em 20 de agosto de 2019.

${ }^{8}$ Disponível em: < https://oscar.go.com/news/oscar-news/oscar-winners-2018-see-the-full-list>. Acesso em 20 de agosto de 2019. 
indiferença supera o medo e a obsessão para culminar em uma troca tão íntima", pela objetividade de "descobre a beleza estonteante do despertar do desejo durante um verão que irá mudar suas vidas para sempre”. Além disso, no livro, a narrativa é conduzida pelo protagonista Elio já adulto, que rememora os acontecimentos e experiências íntimas de um verão na Itália, na década de 1980, onde conhece Oliver (FREITAS, 2018), enquanto o roteiro assinado por Ivory coloca o narrador ao lado de Elio vivendo o presente.

As sínteses do livro e do filme não apresentam conflitos externos que influenciam os protagonistas, e antecipam que ambos enredos levarão o leitor / espectador a uma reflexão existencial a partir das tensões provocadas pelo desenvolvimento de personagens esféricas que, segundo Brait (2004), são aqueles definidos por sua complexidade, apresentam várias qualidades ou tendências, surpreendem convincentemente, são dinâmicas, multifacetadas e constituem imagens totais e, ao mesmo tempo, muito particulares do ser humano. São, assim, seres únicos e de personalidade elaborada, cujo comportamento inesperado tende a manifestar-se, pois traz em si a imprevisibilidade da vida, traz a vida dentro das páginas de um livro (CANDIDO, 2007).

Em entrevista publicada no site da revista Cult ${ }^{9}$ em janeiro de 2018, Aciman afirmou que seu livro traz uma

história absolutamente interna. Tem foco na vida interior dos personagens, [...]. É sobre como examinamos a nós mesmos e a outras pessoas, e nós mesmos frente a outras pessoas. O livro inteiro é contado detalhadamente por Elio, um jovem que constantemente tenta entender quem é, o que quer e o que Oliver quer, pois ele não faz ideia. É sobre ser e descobrir-se. (CULT, 2018)

No contexto da cultura de massa, embora literatura e cinema se apresentam como mídias distintas, as transposições cinematográficas trazem visibilidade às obras literárias (MARTíN-BARBERO e REY, 2004) e tanto o mercado editorial quanto o cinematográfico estabelecem uma relação de abastecimento mútuo ao divulgar e disseminar a mensagem compartilhada por ambos. A prática da comunicação por uma cultura pela paz presente na literatura de Me Chame pelo Seu Nome (2017) tem sua verve de romance de temática homossexual sem traços de violência ou discriminação transposta para a cinematografia, fazendo com que esta mensagem alcance grande público.

Questionado pela jornalista Helô D'Angelo, da revista Cult, por escolher não abordar aspectos violentos no livro, Aciman respondeu:

Eu não queria aquelas típicas situações que sempre aparecem em livros sobre gays. Você sabe, a polícia atacando um casal gay, pessoas cruéis nas ruas batendo neles, alguém infectado com HIV. Eu não queria nada disso no meu romance. Eu queria imaginar: como seria a vida se um casal gay não tivesse de passar por nenhuma dessas coisas violentas e sem sentido? [...] Quando você lê um livro assim, em que não há o lado de fora - ou que ele não importa tanto -, você é inevitavelmente confrontado com o interior dos personagens. Em Me Chame pelo Seu Nome, você precisa olhar para dentro desses dois indivíduos que calharam de ser homens e que estão atraídos um pelo outro, mas sem perigos externos. E aí, o que acontece? É isso que eu queria explorar, e não toda a política, a perseguição, a condenação e a violência ao redor de uma relação assim. [...] A violência sempre está presente: mulheres são perseguidas, gays, minorias. [...] Mas a violência não pode impossibilitar o amor. O medo ou a expectativa de que algo ruim aconteça não podem barrar o romance. Não se pode viver assim. Eu não estava sendo idealista. Eu só não acho que é importante falar sobre isso todo o tempo. [...] Eu sei que a violência existe, e eu tenho certeza que ela está muito presente no Brasil, mas eu não queria que fizesse parte da história. Eu não queria que a perseguição alimentasse um par de personagens estereotipados. (CULT, 2018)

${ }^{9}$ Disponível em < https://revistacult.uol.com.br/home/entrevista-andre-aciman-me-chame-pelo-seu-nome/>. Acesso em 18 de agosto de 2018. 
Ao não abordar temas ligados à LGBTIfobia, Aciman pode causar estranheza nos leitores que tendem a cobrar da representação artística uma relação mais próxima entre realidade e ficção. Principalmente no Brasil onde, segundo o relatório ${ }^{10}$ do Grupo Gay da Bahia (GGB), em 2018, foram registradas 420 mortes por homicídio ou suicídio decorrente da discriminação de pessoas LGBTIs.

Quanto à necessidade de representação por identificação junto ao público, podemos agregar o conceito de mímese, a imitação da realidade, para a qual é preciso certas regras de verossimilhança, já que esta situa a mímese nas fronteiras ilimitadas do 'possível' (DA COSTA, 1992). Porém, Aciman evoca uma leitura mais introspectiva, subjetiva e de caráter psicológico e que pode nos levar ao questionamento de uma possível estratégia de comunicação ao deslocar o foco narrativo de uma violência direta e estrutural, institucionalizadas pelos aspectos de uma cultura (GALTUNG, 2003). O autor estaria colocando em prática uma comunicação não violenta ao adotar alternativas de mediação para a transformação de conflitos por meio da literatura - e veremos, mais adiante, como essa estratégia é mantida no filme.

Em seu discurso, Aciman reconhece a existência da violência, principalmente para com os grupos sócio-acêntricos (chamados por ele, na entrevista, de minorias) e, mesmo assim, reforça sua convicção de que não é preciso olhar para as violências em demasia, tão pouco criar situações violentas que acabam por articular construções estereotipadas de personagens para uma narrativa. Ao reforçar a construção e a individualidade complexa dos personagens, parece que o autor provoca o leitor, talvez identificado com os conflitos internos apresentados na obra, e, assim, estando mais aberto para a reflexão e empatia com as questões do público homossexual.

Segundo o doutor em Ciências Sociais pela Universidade de Buenos Aires, Adrián Melo, a literatura gay não é um gênero, mas sim um ato político, um posicionamento da militância gay e cujo processo de seleção, produção e evolução segue as regras do campo literário (MELO, 2011). Assim, da mesma forma que a literatura cria uma identidade universal pautada pelos marcos regulatórios heterossexuais ${ }^{11}$, também cria uma identidade e literatura homossexual.

[...]a literatura pode fornecer inflexões diversificadas para a exploração da sociedade: pode ser usada como fonte de informação, como chave para uma análise sócio-histórica, e como expressão individual para coletar informações que ajudem a compreender passado, presente e futuro. (MELO, 2011)

\section{O DISCURSO PELA PAZ DENTRO DA NARRATIVA}

No livro, o personagem Elio relembra quando foi retirado de seus pensamentos entre o piano, os livros e a piscina, a boa comida, música e artes, para receber o estudante de pós-graduação Oliver. Durante seis semanas, o convidado americano seria orientado pelo professor Perlman, pai de Elio, e também trabalharia como seu assistente, enquanto aproveitava a casa de veraneio e as atividades locais. Este foi o cenário propício para o encontro e a comunicação de descobertas entre Elio e Oliver, já que ambos têm condições socioeconômicas privilegiadas e vivem em um ambiente de aparente liberdade: o primeiro, por ser um prodígio e ter na família um estímulo para seu aprimoramento individual e, consequentemente, para o desenvolvimento da liberdade (FREITAS, 2018); e o segundo, por estar em um contexto de oportunidade para adquirir melhorias pessoais, no caso, educacional e intelectual, como também aponta Freitas (2018).

Reside em Elio o desejo pelo corpo de Oliver que, por sua vez, precisa lidar com o tabu do sexo com outro homem. A tensão entre desejo e distância na relação dos personagens é reforçada por Aciman quando dos momentos que levam o leitor a vivenciar a permissividade dos corpos seminus à beira da piscina, o toque das peles expostas ao som, a falta do que fazer em meio ao entediante verão, os joguinhos envolvendo moradoras de um vilarejo local, o primeiro beijo, a expectativa pela primeira noite de amor e o constrangimento da desco-

\footnotetext{
${ }^{10}$ Mortes Violentas de LGBT+ no Brasil - Relatório 2018. Disponível em < https://grupogaydabahia.files.wordpress.com/2019/01/ relat\%C3\%B3rio-de-crimes-contra-lgbt-brasil-2018-grupo-gay-da-bahia.pdf> Acesso em 28 de agosto de 2019.

11 "A sexualidade nas sociedades ocidentais tem sido estruturada dentro de enquadramentos sociais extremamente punitivos, e tem disso sujeita a controles formais e informais" (RUBIN, 2003)
} 
berta sexual quando Elio se masturba com um pêssego, todos aspectos evidenciados pelo roteiro de Ivory e pela cinematografia de Guadagnino ao tencionar a estética entre os atores Timothée Chalamet e Armie Hammer.

A transformação de conflito proposta por Aciman ao mostrar um diálogo franco entre pai e filho após os desdobramentos da relação entre Elio e Oliver. Longe do estereótipo do pai opressor, preconceituoso e homofóbico, o professor universitário Perlman compõe a atmosfera que permite a Elio encarar suas descobertas ao Ihe proporcionar uma educação intelectual baseada na experiência, no diálogo e na reflexão. A tônica deste argumento ocorre quando o pai surpreende o filho (e o leitor, ao mesmo tempo) ao se posicionar sobre o relacionamento gay por ele identificado. Levamos em consideração toda uma literatura de temática homossexual que reforça o perfil da autoridade paterna como um marco regulatório resultante de uma heterossexualidade compulsória (BUTLER, 2018).

Em uma pequena lista dos últimos três anos podemos citar personagens como o pai de Boy Erased - Uma Verdade Anulada (Intrínseca, 2019), que obriga o filho a seguir um programa de conversão baseado em um estudo religioso para se tornar heterossexual; o pai de $O$ Fim de Eddy (Planeta Editora, 2018), cujo perfil machista é um reflexo do conservadorismo e do preconceito de uma sociedade no interior da França e que se contrapõe à sensibilidade do despertar sexual do jovem; e o pai de As Fúrias Invisíveis do Coração (Companhia das Letras, 2017), que invisibiliza as descobertas sexuais do filho adotivo em uma sociedade irlandesa que não tolera a homossexualidade.

No quadro abaixo, apresentamos o empático diálogo entre o professor Perlman e o filho, Elio, ao abordá-lo sobre o envolvimento afetivo com Oliver e sua previsível partida após as seis semanas de estada, comparando trechos do livro com a cena roteirizada. Nota-se que grande parte do texto literário foi mantida na transposição da literatura para a linguagem audiovisual.

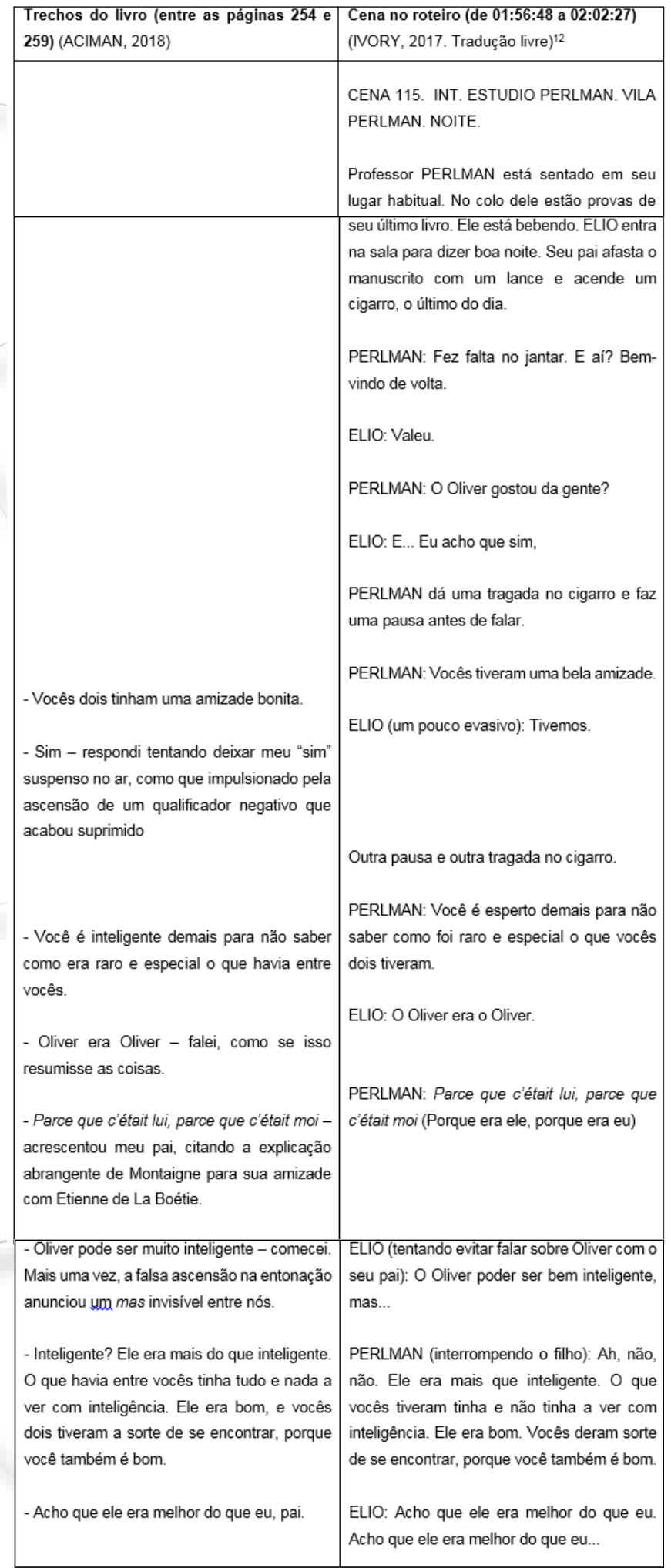

\footnotetext{
${ }^{12}$ Roteiro disponível em <https://sonyclassics.com/awards-information/screenplays/callmebyyourname_screenplay-20171206.pdf> Acesso em 20 de agosto de 2019.
} 


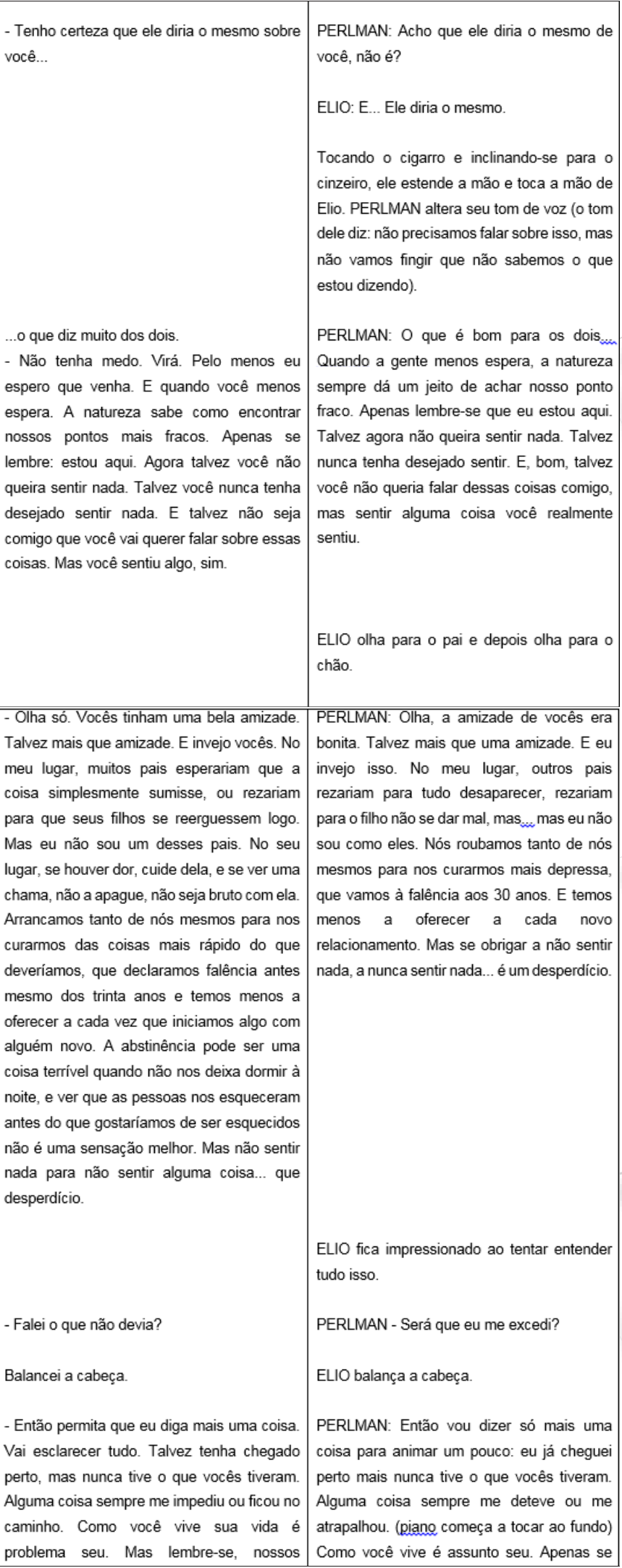

\begin{tabular}{|c|c|}
\hline $\begin{array}{l}\text { corações e nossos corpos nos são dados } \\
\text { apenas uma vez. A maioria de nós teima em } \\
\text { viver como se tivesse duas vidas, uma é a } \\
\text { maquete, a outra a versão final, e todas as } \\
\text { versões entre elas. Mas a vida é só uma, e } \\
\text { antes que você se dê conta, seu coração se }\end{array}$ & $\begin{array}{l}\text { lembre, nós só recebemos um coração e um } \\
\text { corpo uma vez, e quando você percebe seu } \\
\text { coração se desgastou e quanto ao seu corpo } \\
\text { chega uma hora que ninguém quer mais } \\
\text { olhar, nem chegar perto. No momento há }\end{array}$ \\
\hline $\begin{array}{l}\text { cansa e, quanto ao seu corpo, chega um } \\
\text { momento em que ninguém mais olha para ele, } \\
\text { muito menos quer chegar perto dele. Agora } \\
\text { há tristeza. Não invejo sua dor. Mas invejo } \\
\text { sua dor. }\end{array}$ & $\begin{array}{l}\text { PERLMAN respira fundo. } \\
\text { ELIO: A mãe sabe? } \\
\text { PERLMAN: Eu não acho que não. } \\
\text { Mas a maneira como ele diz isso significa } \\
\text { "Mesmo que ela saiba, tenho certeza os } \\
\text { sentimentos dela não seriam diferentes dos } \\
\text { meus". }\end{array}$ \\
\hline
\end{tabular}

logo de Perlman e Elio a prática da empatia. Para Santana, Souza e Mota (2018), empatia e dialogismo crítico marcam, pois, a relação entre pai e filho que, mesmo convivendo à sombra de comportamentos conservadores e excludentes, mostram-se capazes de deslocamentos existenciais que produzem universos transpessoais diversos.

O "monólogo", como ficou conhecida a cena em que o professor Perlman conversa com o filho, que fica pasmo e praticamente sem palavras diante das colocações do pai - marcação que aparece tanto na literatura quanto no roteiro cinematográfico -, encerra os principais eventos do filme e faz com que ele se diferencie da maioria das histórias sobre gays em que os personagens são julgados ou punidos (por seus pais, pares, cônjuges, mentores ou agressores) por sua sexualidade. Cada pausa delicada no "monólogo" é medida para captar o otimismo do filme, como apontou o HuffPost US ${ }^{13}$.

Comparamos trechos do discurso do autor Aciman, por meio do personagem Perlman, que correspondem as características pertencentes à comunicação voltada para paz proposta por Salinas (2014):

${ }^{12}$ Roteiro disponível em <https://sonyclassics.com/awards-information/screenplays/callmebyyourname_screenplay-20171206.pdf> Acesso em 20 de agosto de 2019. 


\begin{tabular}{|c|c|}
\hline Trechos do livro & $\begin{array}{l}\text { Caracteristica de comunicação para a paz } \\
\text { proposta por Salinas (2014) }\end{array}$ \\
\hline $\begin{array}{l}\text { "Agora talvez você não queira sentir nada. } \\
\text { Talvez você nunca tenha desejado sentir } \\
\text { nada. E talvez não seja comigo que você vai } \\
\text { querer falar sobre essas coisas. Mas você } \\
\text { sentiu algo, sim" } \\
\text { "No meu lugar, muitos pais esperariam que a } \\
\text { coisa simplesmente sumisse, ou rezariam } \\
\text { para que seus filhos se reerguessem logo. } \\
\text { Mas eu não sou um desses pais" } \\
\text { "Arrancamos tanto de nós mesmos para nos } \\
\text { curarmos das coisas mais rápido do que } \\
\text { deveríamos, que declaramos falência antes } \\
\text { mesmo dos trinta anos e temos menos a } \\
\text { oferecer a cada vez que iniciamos algo com } \\
\text { alguém novo" }\end{array}$ & $\begin{array}{l}\text { Compreender e refletir sobre os problemas } \\
\text { estruturais. }\end{array}$ \\
\hline $\begin{array}{l}\text { "No seu lugar, se houver dor, cuide dela, e se } \\
\text { ver uma chama, não a apague, não seja bruto } \\
\text { com ela" } \\
\text { "A abstinência pode ser uma coisa terrivel } \\
\text { quando não nos deixa dormir à noite, e ver } \\
\text { que as pessoas nos esqueceram antes do } \\
\text { que gostariamos de ser esquecidos não é } \\
\text { uma sensação melhor. Mas não sentir nada } \\
\text { para não sentir alguma coisa... que } \\
\text { desperdício" }\end{array}$ & $\begin{array}{l}\text { Debater sobre alternativas de mudança social } \\
\text { com o intuito de transformar os problemas } \\
\text { estruturais. }\end{array}$ \\
\hline $\begin{array}{l}\text { "Como você vive sua vida é problema seu. } \\
\text { Mas lembre-se, nossos corações e nossos } \\
\text { corpos nos são dados apenas uma vez. A } \\
\text { maioria de nós teima em viver como se } \\
\text { tivesse duas vidas, uma é a maquete, a outra } \\
\text { a versão final, e todas as versões entre elas. } \\
\text { Mas a vida é só uma, e antes que você se dê } \\
\text { conta, seu coraçãa se cansa e, quanto ao seu } \\
\text { corpo, chega um momento em que ninguém } \\
\text { mais olha para ele, muito menos quer chegar } \\
\text { perto dele" }\end{array}$ & $\begin{array}{l}\text { Reconhecer diversas opiniões, crenças, } \\
\text { percepções ou culturas, favorecendo o } \\
\text { diálogo e o entendimento mútuo. }\end{array}$ \\
\hline $\begin{array}{l}\text { "Você é inteligente demais para näo saber } \\
\text { como era raro e especial o que havia entre } \\
\text { vocês" } \\
\text { "O que havia entre vocês tinha tudo e nada a } \\
\text { ver com inteligência. Ele era bom, e vocês } \\
\text { dois tiveram a sorte de se encontrar, porque } \\
\text { você também é bom" } \\
\text { "A natureza sabe como encontrar nossos } \\
\text { pontos mais fracos. Apenas se lembre: estou } \\
\text { aqui" }\end{array}$ & $\begin{array}{l}\text { Fomentar uma cidadania ativa e ciente das } \\
\text { injustiças. }\end{array}$ \\
\hline
\end{tabular}

Assim, identificamos na possibilidade de uma co- municação para a paz estar presente no conteúdo do livro e, consequentemente, transposto para o cinema, que os autores Aciman e Ivory podem ter atuado como propagadores de uma mensagem que favoreça o diálogo, e que neste momento resolutivo da narrativa de $\mathrm{Me}$ Chame pelo Seu Nome (2017) há uma transformação de conflitos por trás da "moral da história", recurso tão comum às narrativas melodramáticas. Trata-se de uma resolução que está configurada em produtos midiáticos concretos; demonstra a possibilidade de uma nova abordagem de cultura organizacional - neste caso, praticada pela editora e a produtora do filme - que rompa com condutas violentas na produção de produtos culturais; e repercute no público (leitor/espectador) como agente sociocultural que aborda temas carentes de conhecimento e debate na sociedade.

De fato, sendo as organizações expressões socioeconômicas e culturais da vida social, pressupõe-se que sejam, também, reflexos da própria sociedade e, portanto, tendem a traduzir tais manifestações de violência, uma vez que nelas se concentram discursos e práticas que podem legitimar tais violências. [...] a busca por diretrizes normativas, pautadas por instrumentos éticos reguladores da ação das organizações ou defendidas por agentes da mudança organizacional, também tem se apresentado como um movimento crescente extremamente fundamental nesse cenário. Isso indica certo posicionamento crítico da sociedade frente à naturalização da violência no ambiente organizacional. (CABRAL, GONÇALVES e SALHANI, 2018, p. 261).

\section{O DISCURSO DE PAZ INSERIDO EM UM CONTEXTO DE VIOLÊNCIA}

Junto a outras obras com conteúdo LGBTI, em um montante de 14 mil exemplares, o livro Me Chame pelo Seu Nome (2017) foi distribuído gratuitamente na $19^{\mathrm{a}}$

\footnotetext{
${ }^{14}$ Disponível em: < https://g1.globo.com/rj/rio-de-janeiro/noticia/2019/09/07/livros-com-tematica-lgbt-comprados-por-felipe-neto-sao-distribuidosna-bienal.ghtml>. Acesso em 8 de setembro de 2019.
} 
Bienal Internacional do Livro do Rio, em setembro de 2019, em uma ação organizada pelo youtuber Felipe Neto. ${ }^{14} \mathrm{O}$ ato foi uma resposta à determinação do prefeito do Rio de Janeiro, Marcelo Crivella (PRB), que pediu o recolhimento dos exemplares da $\mathrm{HQ}$ Vingadores: A Cruzada das Crianças (2010-2012) por, segundo ele, apresentar "conteúdo sexual" impróprio para menores. A publicação, voltada para adolescentes e jovens adultos, traz a cena de um beijo entre personagens do sexo masculino. ${ }^{15}$

Segundo reportagem publicada pelo site Nexo Jornal ${ }^{16}$, para o professor de direitos humanos e diversidade na Fundação Getúlio Vargas (FGV) de São Paulo, Thiago Amparo, a determinação de Crivella pode ser classificada como censura:

[...] a justificativa legal do prefeito Marcelo Crivella, baseada nos artigos 78-80 do ECA [Estatuto da Criança e do Adolescente] que falam de conteúdo impróprio, inadequado, pornográfico ou obsceno para crianças e adolescentes, é descabida porque pressupõe que o afeto por meio do beijo entre dois personagens masculinos seria algo em si pornográfico, o que não é o caso dada a plena igualdade de direitos de casais LGBTs e heterossexuais. (NEXO, 2019)

Crivella parece apoiar-se em um discurso único e exclusivamente direcionado a pessoas LGBTIs, uma vez que os direitos civis de casais homossexuais são equiparados ao de casais heterossexuais no Brasil desde 2013. Ao nos aproximarmos dos estudos de Galtung, vítima e agressor parecem aqui estarem definidos dentro do conceito de violência direta. No aprofundamento da questão é possível entender também que os agressores estão diluídos em estruturas sociopolíticas, econômicas e culturais desiguais (CABRAL e SALHANI, 2017) e que dão origem a outros níveis e tipos de violências e desigualdades.

Diante desse cenário, cabe-nos relembrar - tal como os alemães relembram do shoá (holocausto) - do equipamento de violência que outrora desenhou um dos períodos mais sombrios da história do Brasil: a Ditadura Civil-Militar (1964-1985) e seus graves crimes contra os Diretos Humanos. Torna-se preciso refletir como as repressões atuais, veladas em ações autoritárias e apoiadas no discurso de defesa da tradição, dos costumes, da nação, do decoro, da educação, da juventude e do elitismo, transformam-se numa das armas mais potentes dos regimes totalitários (COSTA, 2006) e podem levar a um controle cada vez mais violento na comunicação, nas artes e no desenvolvimento humano.

\section{CONSIDERAÇÕES FINAIS}

Os estudos para a paz são multi e transdisciplinares, o que nos permite analisar a comunicação de mídias distintas (neste caso, livro e filme) e que utilizam o mesmo discurso para divulgar uma cultura não violenta. A obra Me Chame pelo Seu Nome (2017) não fala apenas ao público homossexual, pois, por estar representado em produtos culturais consumidos pela sociedade, ampliam a propagação de uma mensagem de respeito à diversidade em meio a uma audiência menos segmentada.

Nota-se a sensibilidade do autor André Aciman e do roteirista James Ivory, ao elaborarem, adaptarem e divulgarem no "monólogo de Perlman" uma alternativa de transformação de conflitos que pode servir de inspiração aos que não conseguem lidar com as descobertas sexuais dos filhos. Nessa postura, que pode ser interpretada como distante da realidade, a figura do autor/roteirista mostra-se coerente com uma comunicação com foco no desenvolvimento humano, no cultivo de relações pacíficas e em fomentar ações para uma cidadania mais ativa, ciente e focada na transformação das injustiças sociais, ou seja, na certeza de que, assim como aprende-se a viver em uma cultura de violência, é possível fazer a paz criar raízes. A violência não pode impossibilitar o amor.

\footnotetext{
${ }^{15}$ Disponível em: < https://www.nexojornal.com.br/entrevista/2019/09/07/O-momento-regressivo-do-Brasil-segundo-este-constitucionalista> . Acesso em 8 de setembro de 2019.

${ }^{16}$ Disponível em https://www.nexojornal.com.br/expresso/2019/09/06/O-que-h\%C3\%A1-de-ilegal-na-censura-de-Crivella-na-Bienal-do-Rio>. Acesso em 8 de setembro de 2019.
} 


\section{REFERÊNCIAS}

ACIMAN, A. Me chame pelo seu nome. Tradução: Alessandra Esteche. Rio de Janeiro: Intrínseca, 2018.

BARDIN, L. Análise de conteúdo. São Paulo: Edições 70, 2016.

BUTLER, J. Problemas de gênero: feminismo e subversão da identidade. Tradução: Renato Aguiar. 16. ed. Rio de Janeiro: Civilização Brasileira, 2018.

BRAIT, B. A personagem. São Paulo: Editora Ática, 2004.

COSTA, C. Censura em cena. Teatro e Censura no Brasil. O arquivo Miroel Silveira. São Paulo: Edusp \& Imprensa Oficial, 2006.

COSTA, L. M. A poética de Aristóteles: mímese e verossimilhança. São Paulo: Ática, 1992.

CALL ME BY YOUR NAME. Direção: Luca Guadagnino. Produção: La Cinéfactures, Frenesy, RT Features, Itália/França, 2017. 1 bobina cinematográfica (132min), son., color., $35 \mathrm{~mm}$.

CABRAL, R; SALHANI, J. Jornalismo para a paz: conceitos e reflexões. Revista da Associação Nacional dos Programas de Pós-Graduação em Comunicação. E-compós, Brasília, set./dez. 2017.

CABRAL, R; Gonçalves, G; SALHANI, J. Violência organizacional: reflexões a partir da perspectiva dos estudos para a paz. Organicom - Revista Brasileira de Comunicação Organizacional e Relações Públicas / Departamento de Relações públicas, Propaganda e Turismo, Escola de Comunicações e Artes, Universidade de São Paulo. São Paulo: ECA-USP, 2018.

CANDIDO, A. (Org.). A personagem de ficção. São Paulo: Editora Perspectiva, 2007.

FEBVRE, L; MARTIN, H-J. O aparecimento do livro. São Paulo: Edusp, 2017.

FREITAS, C. $O$ desejo de si e o falso amor em
Call Me By Your Name. Intercom: Joinville, 2018. Disponível em: <http://portalintercom.org.br/anais/nacional2018/resumos/R13-1983-1.pdf>.

GALTUNG, J. Violencia cultural. Tradução do inglês: Teresa Toda. Edição em castelhano: Gernika Gogoratuz, 2003.

IVORY, J. Call Me By Your Name. Screenplay based on the nove by Andre Aciman. Sony Classics: 2017.

MARTÍN-BARBERO, J.; REY, G. Os exercícios de ver: hegemonia audiovisual e ficção televisiva. Tradução de Jacob Gorender. São Paulo: Senac São Paulo, 2004.

MELO, Adrián. Historia de la literatura gay em Argentina. Buenos Aires: Ediciones Lea, 2011.

NOLETO, M. J. A construção da cultura de paz: dez anos de história in Cultura de paz: da reflexão à ação; balanço da Década Internacional da Promoção da Cultura de Paz e Não Violência em Benefício das Crianças do Mundo. Brasília: Unesco; São Paulo: Associação Palas Athena, 2010.

RUBIN, G. Pensado o sexo: notas para uma teoria radical das políticas da sexualidade. In: Cadernos Pagu, n. 21, 2003.

SALINAS, A. I. A. Periodismo y comunicación para la paz. indicadores y marco regulatório. Revista Comunicación y Cidadania Digital - COMMONS.

SANTANA, J. A.; SOUZA, J. B. de; MOTA, A. A. de $S$. Sonhos do avô, do pai e do filho ou sobre polifonias psicoculturais contemporâneas em Me Chame pelo Seu Nome / Call Me By Your Name, de André Aciman. Artfactum - Revista de Estudos em Linguagem e Tecnologia, 2018.

SPANGLER, B. Settlement, resolution, management, and transformation: an explanation of terms. In Beyond Intractability. Eds. Guy Burgess and Heidi Burgess. Conflict Information Consortium, University of Colorado, Boulder. Posted: September 2003. Disponível em: <http://www. beyondintractability.org/essay/meaning-resolution>. 